\title{
Converging Andragogy With Working Adult Professionalism in Initial Teacher Preparation
}

\author{
Michelle Anderson, EdD
}

Aquinas College, Grand Rapids, Michigan, United States

iD https://orcid.org/oooo-0001-8764-5343

Stefani Boutelier, $\mathrm{PhD}$

Aquinas College, Grand Rapids, Michigan, United States

(iD https://orcid.org/oooo-0o01-9039-9913

Contact:mraoo3@aquinas.edu

\begin{abstract}
Educator Preparation Programs (EPPs) are tasked with providing preservice teachers with pedagogical theory, practical field experiences, mentorship, and scaffolded professional dispositions during critical phases of their preparation. In addition, EPPs collaborate with school districts and state departments of education to address critical issues in the field, including teacher retention and shortages. Our research explores how one EPP pilot, designed to build upon experience, supported working adult education students (e.g., parapros) seeking initial teacher certification. We sought to understand how adult teacher candidates engaged in professional learning and emergent professional relationships. Our qualitative study examined the experience of the first cohort of a 3-year pilot program. Using andragogy as a conceptual framework and paired with Danielson Evaluation Dispositions to expand on this professionalism, the data expanded on these professional dispositions through a thematic network analysis. Emerging from this analysis and through an andragogical lens, cohort members exhibited key traits associated with adult learners, including application of skills, flexibility, identification of growth, and relationship building. Our research concluded with implications for EPPs and suggestions for further research for programs at the intersections of andragogy and initial teacher certification.
\end{abstract}

Keywords: adult learners, andragogy, cohort, EPPs, teacher preparation

Date Submitted: April 7, 2021 | Date Published: September 15, 2021

Recommended Citation

Anderson, M., \& Boutelier, S. (2021). Converging andragogy with working adult professionalism in initial teacher preparation. Journal of Educational Research and Practice, 11, 202-216.

https://doi.org/10.5590/JERAP.2021.11.1.14

\section{Introduction}

Reaction to the shortage of teachers in training must be addressed with innovative, immediate, and purposeful routes (Berry \& Shields, 2017; Downey, 2021). From a strategic and creative lens, schools of education must provide "support for teacher learning..." while "evaluation must be part of an integrated whole that enables effectiveness during every stage of a teacher's career" (Darling-Hammond, 2012, p. 9). A key component of a successful teacher preparation program is a supportive environment with experienced mentor 
teachers and leaders who promote reflection and improvement (The Sustainable Funding Project, 2016). Our study looked at adult learners and how reflection and improvement demonstrated emergent professionalism in teaching to seamlessly integrate/connect to maturity, utilize professional experience, and expand on lived realities to adhere to a transfer of formal education through unpredictability and real-world application (Halpern \& Hakel, 2003, p. 3). This research supports Martin's (2019) acknowledgment of reflective practices among a group or culture to interpret social meaning and enhance outcomes, thus, interweaving the researcher/faculty understanding of the effectiveness of adult learning needs and teacher retention essentials. Our research explored professionalism with adult (i.e., nontraditional-aged college students) preservice educators through a pilot program (at a small liberal arts college in the Midwest) to better understand increased retention and preparation for PK-12 teachers. The program was designed to educate working adults (e.g., those who have completed their undergraduate education and have full-time work experience in any field) who wanted to obtain teacher certification in education. There is a missing distinction of how to support adult learners in the education field. Ultimately, we sought to understand how adult preservice teachers engage in professional learning. We explored the intersections of andragogy as a conceptual framework with teacher preparation. We first present the literature; then we discuss the methodology, findings, and implications for adult professional learning in educator preparation programs (EPPs).

\section{Andragogy as a Framework}

Our research was framed through andragogy-moving beyond the umbrella term of pedagogy-to better understand and support adult learners. From this lens, andragogy is informed and designed by incorporating concepts of learning as a product (relevancy), natural growth and self-involvement (convenience), studentcentered and learner-evaluated (exploration), and a process to gain mastery in the intended topic (immediacy) (Knowles et al., 2015; Pappas, 2014). This intersects the use of praxis and modeling the application of engaging a clear connection and transition of theory into practice for educators (Freire, 2000; $\mathrm{Hu}, 2020$ ) and taking advantage of students' professionalism gained from previous experience. Our use of andragogy as a framework for this study was guided by the gap in literature at the crossover of adult learning theory and teacher professional relationships.

\section{Adult Learning Theory}

A majority of EPPs are designed for traditional undergraduate students, ages 18-22. Pedagogy then seeks to engage these learners in the process of instruction and learning that, according to Knowles et al. (2015), too often assumes learning is subject oriented and that previous experience is not relevant to learning. What happens when EPPs expand programming to include graduate students? These processes provide limited alignment with adult learners' needs-the opposite of what is found in the adult learning theory of andragogy (Walsh et al., 2005). Andragogy is "the art and science of helping adults learn, in contrast to pedagogy as the art and science of teaching children” (Knowles, 1980, p. 43). Merriam (2001) asserts the study of andragogy separates adult learning from other areas of education, focusing on the process and context of adult learning. This includes, but is not limited to, creating learning environments where adult learners can apply their experiences.

Adult learners thus take on a self-directed approach to learning, pivoting away from the teacher-directed, learner-dependent model emphasized in traditional pedagogical settings. The exploration by Hagen and Park (2016) of the cognitive sciences as it relates to andragogy implies that learning experiences for adults should focus on competency, life situations, and application to real-world problem solving. This approach emphasizes the importance of learning with direct application. Similar findings are outlined in the study by Walsh et al. (2005) of adult learner experiences in a graduate education program where learners desired practical and usable information. Adult learners praised course content that allowed for direct application of strategies that could be used in the classroom, such as lesson planning and field experiences. 


\section{Professional Relationships}

Knowles (1975) defined self-directed learning as a process adults undertake individually or with the help of others. During this process, the learner identifies their needs and goals, assistive resources and strategies, ultimately evaluating learning outcomes. The process can be supported by working with a cohort. In particular, the peer group is an important motivating factor in self-directed learning (McCartney et al., 2016). Shared professional experiences allow learners to engage in the process previously outlined to evaluate their learning outcomes and reassess their learning needs. Similarly, participation in a teacher education cohort model provides opportunities for collaboration with peers, instructors, mentors, and field supervisors. The nature of cohort models allows for relationship building. Studies have demonstrated that cohort models foster interpersonal relationships, provide a sense of belonging, and build trust (Dinsmore \& Wenger, 2006; Mello, 2003). The study by Walsh et al. (2005) also highlights the cohort structure as a means for relationship building where learners trusted one another, learned to work together, and offered a supportive learning environment.

The cohort model functions as a professional learning community (PLC) variant for adult students to build relationships. Relationships develop among colleagues, instructors, and mentors in the field. Forging a strong support system can assist with teacher satisfaction, leading to teacher retention. Kuh's (2009) model of adult student engagement showed that their resolve to succeed depended on their engagement with their education. Tinto (1994) suggested that adult students are more engaged if they connect with other members of the learning community. Members of PLCs work together to practice skills, implement strategies, and work in a collegial manner with their peers over an extended period of time (Darling-Hammond \& Richardson, 2009; Meiers et al., 2009; Owen, 2014). PLCs take time to cultivate. Early stages of PLCs can be superficial without forging strong relationships among colleagues. As the PLC matures, relationships are strengthened while encouragement and collaboration grows for effective support (Owen, 2016). It is clear that PLCs are effective when engaged and supported over the long term; however, a deeper understanding of professional learning as introduced and structured during the teacher preparation phase is needed.

\section{Context}

The Michigan Department of Education (MDE) identified retention of teachers as a priority because of teacher shortages and a 15-year decline in education major graduates (CALDER, 2021; Regional Educational Laboratory Midwest, n.d.). The MDE approved a 3-year pilot program-an Accelerated Master in Education program at a small liberal arts college in Michigan-to start in the academic year of 2019-2020. This program responded to the increased need to retain and attract successful educators in the PK-12 system and for effective teacher programs to fulfill forecasted shortages (Downey, 2021; U.S. Department of Education, 2021; Walker, 2019) by designing this program for working adults (see Appendix A).

Understanding how to best recruit and support adult learners in preservice education preparation is a key component to long-term retention. In light of the School of Education's focus on meeting the needs of a diverse body of students and the MDE's approval of this accelerated initial certification graduate pilot program, we sought to further understand how adult preservice teachers engage in emergent professional relationships.

\section{Methods}

We used traditional qualitative data collection through surveys, student reflections, and panel interviews to understand how adult learners engage in professional learning. The preliminary instruments solely collected data from the first cohort (i.e., year 1 of the pilot study). The respondents included adult students' (see Table 1) and support (e.g., clinical supervisor, cooperating teacher, faculty, or staff) team members' reflections and a group exit interview (observational data from this was provided by the Dean of the School of Education). This 
data collection took place over the course of one academic year. The variation of data collection and participants echoed the use of "scaffolding ... defined in this study as fluid, unfolding, occasionally competing or overlapping, sequences of actions in conversation that gradually take shape as a narrative" (Martin, 2019, p. 1283). This scaffolding of data provided a structure for the evaluation of the long-term goals of the program identified in our research and highlighted missing andragogical support systems. In addition, our research also acted as a formative evaluation-from Cohort 1-of the program by focusing on converging working adult experience with teacher preparation in real time, for ongoing redesign.

The adult student cohort under examination included 10 members with a variety of backgrounds (see Table 1). Though none of the participants pursued education as a major in their undergraduate work, all held positions in classrooms at the time of application to the program. The teachers of record in the classroom were those in private schools or who had emergency certification because of the current teacher shortage in the state.

Table 1. Cohort Demographics $(n=10)$

\begin{tabular}{|c|c|c|c|}
\hline Age & No. of Participants & Bachelor's Degree & No. of Participants \\
\hline $22-29$ & 6 & Biology/Health Sciences & 3 \\
\hline $30-39$ & 1 & Business & 1 \\
\hline $40-49$ & 2 & Communications & 3 \\
\hline \multirow[t]{2}{*}{$50-59$} & 1 & History/Social Studies & 2 \\
\hline & & Theology & 1 \\
\hline Gender & \multicolumn{3}{|c|}{ Teacher Certification Completion } \\
\hline Male & 3 & 12 months & 9 \\
\hline \multirow[t]{4}{*}{ Female } & 7 & 16 months & 1 \\
\hline & \multicolumn{3}{|c|}{ Initial Certification Band } \\
\hline & & Elementary & 4 \\
\hline & & Secondary & 6 \\
\hline
\end{tabular}




\section{Thematic Network Analysis for Data Analysis}

Our data analysis used a methodical process to integrate codes through generalized themes based on specific program dispositions. Specifically, we used a thematic network analysis framework that involved the predetermined global themes of Danielson's Disposition Expectations Domain 4 (see Appendix B), organizing themes (coding and categorized through the data), and basic themes (coded through direct participant responses). This thematic process helped "remove any notion of hierarchy" through the analysis of our data set (Attride-Stirling, 2001, p. 389).

After organizing and scanning the available data, we initially and individually analyzed the data to ensure all six criteria of the Danielson Professional Domain 4 dispositions were supported. These domains were identified as global themes in our analysis process because they are part of a large group of expectations that guide our outcomes in the initial certification curriculum. The fourth Danielson Domain has six criteria for professionalism: 4a. reflecting on teaching, 4b. maintaining accurate records, 4c. communicating with families, 4d. participating in a professional community, 4e. growing and developing professionally, and $4 \mathrm{f}$. showing professionalism (Danielson Group, 2014). Through our first round of blind coding, we individually pulled out themes where we honed in on Danielson Domain 4, which not only provided the most data but also engaged in findings that would answer the research question (Braun \& Clarke, 2006; Miles et al., 2020). With a crossover of patterns in our discussion, the data showed that three domains stood out and indicated the enhancement of andragogy through professional learning. The three we further investigated and analyzed as organizing themes were 4a. reflecting on teaching, 4d. participating in a professional community, and 4e. growing and developing professionalism that directly supported andragogy as a framework. Through a tighter, collaborative round of coding of the data for the three organizing themes, four basic themes emerged: (1) identification of growth, (2) application of skills, (3) relationship building, and (4) flexibility (see Figure 1).

Figure 1. Thematic Network Analysis of Data

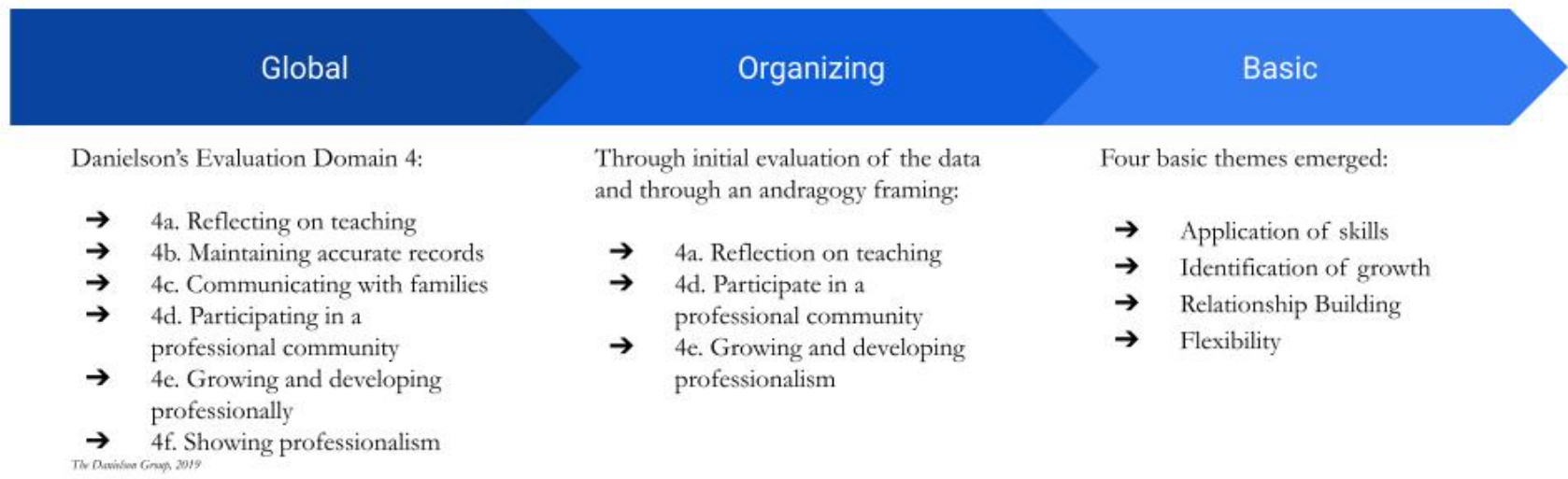

Limitations through the data collection process included variations in prior experience (see Table 1), a limited number of participants from a small liberal arts college, and a multiplicity of current work experience that influenced adult learning. Because this was the first year of the pilot, it was difficult to discern if the pivot to online learning due to COVID-19 influenced cohort responses during the unknown and consistently shifting dynamics of pandemic regulations. Trustworthiness was strengthened through the guided use of thematic network analysis and confirmation through blind- and cross-coding (Miles et al., 2020; Nowell et al., 2017). With the extension of the three focused Danielson Domains into four themes (identification of growth, application of skills, relationship building, and flexibility), we presented findings and implications concurrently with a paralleled analysis of adult learning modes (i.e., andragogy) to understand professionalism in an EPP. 


\section{Findings and Implications}

It was clear through the initial analytical lens of viewing the data with the Danielson Domain 4 subsections that faculty, mentors, and other team members not only need to teach and model these domains, but there is also a need to evaluate students' understanding and application of these domains. The data displayed a crossover of andragogy and Danielson Domain 4; the themes pulled out are described implicitly to further support adult preservice teachers (see Figure 2). The findings and analysis are presented simultaneously to provide evidence along with the implications. Cohort members' direct responses are presented in italics.

Figure 2. Visual Representation of Key Findings of Professionalism in Initial Teacher Certification

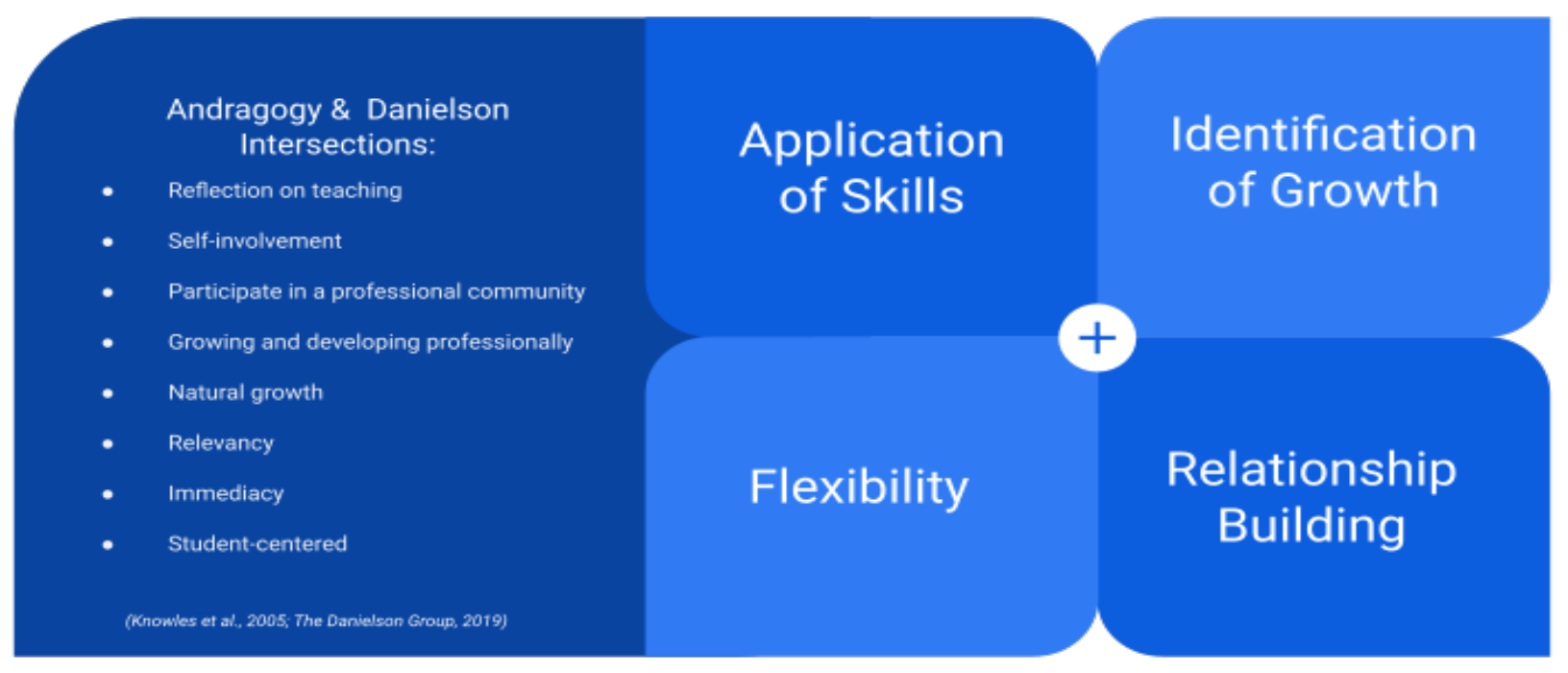

\section{Identification of Growth}

The identification of growth theme mirrors the emphasis of Danielson Domain 4a.-Reflection on teaching. This domain stresses the importance of evaluating instruction. Methodically thinking about instructional moves and student responses helps teachers determine effectiveness, identifying what worked and what did not. Teachers engaged in this process by conversing with colleagues, assessing student work, and journaling. In developing these abilities, members of the cohort oriented themselves away from a subject-centered focus to a problem-based focus (Knowles et al., 2015).

Our findings indicated cohort members were able to identify areas where their instruction was effective through observation and reflection. One adult teacher candidate referenced differentiated instruction as an area of growth, stating, I have been able to adapt lessons for students' individual needs and have my students go at their own pace. This is something I have noticed a lot of teachers struggle with. Another cohort member emphasized:

I find that I am constantly asking myself how I could have done things differently to make a situation better, whether that's a conversation with a student, leading one-on-one conversations with students about the book they read to me, or introducing a lesson to a class on a spur-of-themoment step-in. I'm always reflecting on how I can better myself in my role for the "next time."

These responses are demonstrative of shifting perspectives on behalf of the cohort member to the bigger picture of what comes next. As identified by Knowles et. al (2015), they are using their experiences as a 
resource for their own learning. Paired with the emphasis Danielson places on reflection, students were able to acknowledge their instructional growth.

However, we did find some responses to be superficial; some cohort members did not internalize classroom events or preparation to reflect on instruction or student achievement. Opportunities to reflect on student learning and growth were overlooked, and members exemplified the need to immediately apply information, as evidenced by this participant:

I struggled a lot with the different assignments that we had to do occasionally for different professors because I didn't see the point in them. It is only later on that I understand the value and importance of a lot of those assignments.

To address the incongruence, future studies regarding the alignment of coursework with application in the field and individual experiences may help students better unpack and process instructional goals within the program. In addition, exploration and integration of adult growth goals may assist with programmatic review, yielding changes to support future cohorts.

\section{Application of Skills}

The discovered theme of application of skills echoes Danielson's criterion 4e.-Growing and developing professionally. This criterion includes areas of enhancement, active participation, being current with instructional research and strategies, and professionalism (Danielson Group, 2014). The organizing themes under growing and developing largely focus on the growth aspect. The distinction from Danielson's 4e. Domain in this theme is the increase and identification of skill level, immediacy of application, growth in content and methods, and refining innovative design. As Knowles et al. (2015) state, adult learners need tangible learning products, self-involvement, and intention for transfer.

To support this theme, cohort members unknowingly acknowledged elements that identify their adult learning needs. One cohort member stated workshops were intentional and streamlined while another was aware how they easily transfer the knowledge we are learning into our every day jobs. As well, one participant noted that the aim of the program helped me to focus on skills more than content. It has allowed me to think and plan "outside of the box" to further support application of skill and adult needs of intentional strategies.

This application was enhanced by the teacher candidate learning and teaching at the same time. Examples of this in the field included evidence to use skills and knowledge in an authentic setting, able to adapt lessons for students' individual needs, and a third mentioned the importance of having hands-on experience going on at the same time. The application of skills is not solitary; it overlaps (as expected) with other key themes. One participant noted the benefit of reflecting back on how a teaching strategy worked, didn't work, and what I'd change about it through application in their classrooms. This suggests the importance of concurrent teaching and learning for the adult preservice educators in this program.

Placing theory into practice, paired with opportunities for reflection, can enhance how adult preservice educators approach teaching and learning in the classroom. Yet, the anomaly of EPPs overlapping application of pedagogy and methodology while simultaneously teaching (versus traditional undergraduates who learn and then apply later) spurs further investigation on the effect immediate application of skills has for consistent long-term implementation.

\section{Relationship Building}

The third theme of relationship building correlates with Danielson Domain 4d.-Part of a professional community, with a focus on relationships with colleagues, service to the school, and inquiry in the profession. 
Teachers plan with one another, supporting the school community and improvement initiatives (Danielson Group, 2014). Knowles et al. (2015) acknowledged that adults learn best from experiences. The Danielson Evaluation places emphasis on teachers working together to improve instructional skill and student success. The data revealed members of the cohort identified relationships with colleagues in three distinct areas based on their experience: (1) program instructors, (2) mentor teachers, and (3) the cohort itself. Through their experience with these three groups, the cohort engaged in building relationships that allowed them to grow as professionals.

\section{Program Instructors}

Cohort members identified modeling done by program instructors as influential to their own approach in the classroom. As one participant stated, the professors were great examples for us as to how we should be with our students in a class. Modeling for the cohort allowed for direct crossover of the identified themes of application of techniques and approaches in the classroom. As noted by Knowles et al. (2015), adult learners are motivated when they can apply new ideas to work situations. This motivation is demonstrative in responses from members of the cohort concerning class discussions in noting, professors were engaging and opened up a platform that allowed us to be raw with questions and inquiries about teaching and they were very flexible and willing to let us have in depth conversations even though we may have skipped some activities or ran out of time. These conversations allowed the cohort to unpack ideas and raise questions. This process mirrors the indicator in the Danielson Evaluation identifying teacher participation in professional courses or communities that emphasize improving practice.

\section{Mentor Teachers}

Building on the modeling by instructors in classes, mentor teachers continued guiding cohort members in the classroom. Work with mentor teachers allowed cohort members to become colleagues who shared and planned for student success. Reflection and feedback guided learners through this self-directed process. Selfdirected learning allowed the learner to identify what they needed to know and evaluated their learning outcomes (Knowles et al., 2015). One cohort member identified the guidance provided by the mentor teacher and willingness to share her experience, knowledge and time to make me a better teacher, adding she also taught me the importance of reflective practice. To take them time to understand what went well, what did not and how to adapt. Only after a relationship has formed can cohort members begin to internalize feedback. This was similar to another member identifying that I continue to build professional relationships with the teachers in the building, listening and observing what they have to say, not just to me but to students and how they conduct themselves with their students. Another cohort member reaffirmed this position, stating, I have learned way more than just how to teach but how to build relationships with students and colleagues as well. Building relationships was evident due to the quick pivot to online learning during the COVID-19 crisis. Participants found themselves guiding and teaching other veteran teachers on how to integrate technology into their teaching at a short notice. As these relationships continued to grow, some members of the cohort moved into leadership roles among colleagues in the building.

\section{Cohort}

As relationships developed in the field, cohort members grew together as well. This cohort of educators [became] my friends, allies, and mentors. We learned together, laughed together, and even cried a little together. Our shared journey created an instant bond that allowed us to become reliant on one another. Another participant noted, the experience to do this with a group of individuals as a solid team is essential for the program to be a success. We relied on each other, supported each other, and guided each other during our learning process. Support and guidance are foundational to working relationships. As a cohort, members modeled moving beyond simple classmates to being collegial with one another. In a variety of contexts, they demonstrated professional inquiry with instructors and collaboration with mentors and peers. 
Few, if any, cohort members referenced professional inquiry beyond classroom discussions. In addition, service to the school did not appear in the data collected as identified in Danielson's Domain 4. Implications for EPPs include using the long-term placements (versus the traditional diversity of placements used in undergraduate programs) of their working adult populations in schools for field placement to build stronger relationships, thus leading to long-term retention. Future research should converge the relationships of adult peers and cohorts for adults in initial certification programs.

\section{Flexibility}

The key emergence of flexibility through the data not only supports andragogic principles but also what is needed for a successful educator at the intersection of all of the organized themes, multiple Danielson Domains, and professionalism. The purpose of the Accelerated Master of Education program and the nature of adult learning led to the need to identify one's growth, apply skills, and build important relationships to support their pedagogy in a PK-12 classroom. Flexibility to support peers or seeking and applying feedback during learning events were witnessed throughout the data (not only based on the changing dynamics during COVID-19). One participant summed it up by stating, I have learned how to become truly flexible, effectively collaborate with other educational professionals, and how to design an interconnected curriculum that tailors to all my students' individual culture(s), learning style(s) and need(s)... and added to that flexibility is learning the importance of reflective practice. To take the time to understand what went well, what did not, and how to adapt. The last part of the response, in particular, represents a missed opportunity to elaborate on how the cohort member implemented flexibility in the classroom to meet student needs. Rarely did members identify specific strategies and reflect upon their effectiveness.

Danielson emphasized specificity to assist with self-reflection to make it a habit of mind. To grow in the profession, teachers identify examples to support making adjustments leading to professional growth. While members of the cohort identified areas of growth, strength, and deficit, they require more guidance and practice with reflection to develop self-reflection as a habit of mind. By intersecting the first three themes (i.e., identification of growth, application of skills, and relationship building) with flexibility, we saw the need to continue to employ research-based andragogy across EPPs through immediate application and future research.

\section{Conclusion}

This research originated and expanded to understand how adult learners engaged in professional learning to best respond to the ongoing teacher shortage. Our research guided us to further look at how adult learners might decrease this trend and increase retention with new teachers who were nontraditional-aged students. Through our thematic network analysis, we were able to identify how to best support professional learning through andragogy via application of skills, identification of growth, relationship building, and flexibility. Adult teachers in training need self-directed application of content concurrently with effective collaborative processes for ongoing effectiveness and immediacy.

As with anything, the longer a program exists, the more opportunities arise to reflect and revise the experience. Although the pilot year was impacted by ongoing pivots of settings, experiences, etc. due to COVID-19, the findings provide a strong baseline for the program's growth. Current data reveal participants engaged in building relationships that enhanced their overall experience with the cohort in accordance with key dispositions identified by the program. Maintenance of this characteristic will be integral to success with subsequent cohorts. Reflection on the support team structure in conjunction with the findings from this study provide fertile ground for further inquiry into how the program can more purposefully address relationship building, identification of growth, application of skills, and flexibility as candidates move into their first years of teaching and, potentially, support retention in the field. 
The literature surrounding relationship building focused on cohort models or group learning settings, such as professional learning communities (Darling-Hammond \& Richardson, 2009; Meiers et al., 2009; Owen, 2014). These structures are not completely demonstrative of relationship building as it pertains to andragogy and self-directed learning. As noted earlier, the peer group is an important motivating factor in self-directed learning (McCartney et al., 2016).

Important to future success of any adult-centered EPP is providing program instructors with andragogyenhanced professional development. Consistency across course instruction can support graduate students and enhance their acquisition of professional dispositions in any graduate education program. While limited in its original scope, future research regarding relationship building and its connection to teacher retention would help further the impact of our current study. Dedicating inquiry toward building and supporting peer relationships beyond these settings may glean important data that can be applied to the current literature regarding retention in the field of education. It will also foster the connection between EPP design and the needs of adult learners. This research is necessary and integral as the working adult population grows to fill teacher shortages. 


\section{References}

Attride-Stirling, J. (2001). Thematic networks: An analytic tool for qualitative research. Qualitative Research, 1(3), 385-405. https://doi.org/10.1177/146879410100100307

Berry, B., \& Shields, P. M. (2017). Solving the teacher shortage: Revisiting the lessons we've learned. Phi Delta Kappan, 98(8), 8-18. https://doi.org/10.1177/0031721717708289

Braun, B., \& Clarke, V. (2006). Using thematic analysis in psychology. Qualitative Research in Psychology, 3(2), 77-101. https://www.tandfonline.com/doi/abs/10.1191/1478088706qpo63oa

CALDER. (2021). Aggregated number of graduates in education by state. CALDER: National Center for Analysis of Longitudinal Data in Education Research. Retrieved March 11 https://caldercenter.org/data-visualizations/aggregated-number-graduates-education-state-o

Danielson Group. (2014). Correlation between the Danielson Framework for Teaching and the Interstate Teacher Assessment and Support Consortium (InTASC) Standards. https://danielsongroup.org/downloads/correlation-framework-teaching-intasc-standards

Danielson Group. (2019). The Danielson Framework. https://homepages.dsu.edu/gwiedow/CAEP/63.DanielsonFrameworkcorrelationwithInTASC.pdf

Darling-Hammond, L. (2012). The right start: Creating a strong foundation for the teaching career. Phi Delta Kappan, 94(3), 8-13. https://doi.org/10.1177/003172171209400303

Darling-Hammond, L., \& Richardson, N. (2009). Research review. Teacher learning: What matters? Educational Leadership, 66(5), 46-53.

Dinsmore, J., \& Wenger, K. (2006). Relationships in preservice teacher preparation: From cohorts to communities. Teacher Education Quarterly, 33(1), 57-74.

Downey, M. (2021, January 11). Fewer college students choose teaching. Will COVID dissuade more? The Atlanta-Journal Constitution. https://www.ajc.com/education/get-schooled-blog/fewer-collegestudents-choose-teaching-will-covid-dissuade-more/4SSBRDQAR5HVJNCLBYWZ3TRUOA/

Freire, P. (2000). Pedagogy of the oppressed: 3oth anniversary edition. Bloomsbury.

Hagen, M., \& Park, S. (2016). We knew it all along! Using cognitive science to explain how andragogy works. European Journal of Training and Development, 4O(3), 171-190. https://doi.org/10.1108/EJTD-102015-0081

Halpern, D. F., \& Hakel, M. D. (2003). Applying the science of learning to the university and beyond: Teaching for long-term retention and transfer. Change: The Magazine of Higher Learning, 35(4), 36-41. https://doi.org/10.1080/00091380309604109

$\mathrm{Hu}$, C. C. (2020). Understanding college students' perceptions of effective teaching. International Journal of Teaching and Learning in Higher Education, 32(2), 318-328.

https://www.isetl.org/ijtlhe/pdf/IJTLHE3795.pdf

Knowles, M. S. (1975). Self-directed learning: A guide for learners and teachers. Follett. https://doi.org/10.1177/105960117700200220

Knowles, M. S. (1980). The modern practice of adult education: From pedagogy to andragogy. Cambridge.

Knowles, M. S., Holton, E. F., III, \& Swanson, R. A. (2015). The adult learner: The definitive classic in adult education and human resource development (8th ed.). Routledge. https://doi.org/10.4324/9781315816951

Kuh, G. D. (2009). What student affairs professionals need to know about student engagement. Journal of College Student Development, 5o(6), 683-706. https://doi.org/10.1353/csd.o.0099 
Martin, J. (2019). Researching primary teachers' professional agency: Employing interactive ethnography to overcome reluctance to teach science. Research in Science Education 49(5), 1279-1299. https://doi.org/10.1007/s11165-017-9654-y

McCartney, R., Boustedt, J., Eckerdal, A., Sanders, K., Thomas, L., \& Zander, C. (2016). Why computing students learn on their own: Motivation for self-directed learning of computing. ACM Transactions on Computing Education (TOCE), 16(1), 2. https://doi.org/10.1145/2747008

Meiers, M., Buckley, S., \& Knight, B. (2010). Successful professional learning. The Digest, 201O(1). NSW Institute of Teachers.

Mello, R. A. (2003). The integrated cohort program: An evaluation of a pre-professional course of study. The Educational Forum, 67(4), 354-363. https://doi.org/10.1080/00131720308984584

Merriam, S. (2001). Andragogy and self-directed learning: Pillars of adult learning theory. New Directions for Adult and Continuing Education, 2001(89), 3-14. https://doi.org/10.1002/ace.3

Miles, M. B., Huberman, A. M., \& Saldaña, J. (2020). Qualitative data analysis: A methods sourcebook (4th ed.). Sage.

Nowell, S. L., Norris, J. M., White, D. E., \& Moules, N. J. (2017). Thematic analysis: Striving to meet the trustworthiness criteria. International Journal of Qualitative Methods, 16(1), 1-13. https://doi.org/10.1177/1609406917733847

Owen, S. (2016). Professional learning communities: building skills, reinvigorating the passion, and nurturing teacher wellbeing and "flourishing" within significantly innovative schooling contexts. Educational Review, 68(4), 403-419. https://doi.org/10.1080/00131911.2015.1119101

Owen, S. (2014). Teacher professional learning communities: Going beyond contrived collegiality toward challenging debate and collegial learning and professional growth. Adult Journal of Adult Learning, 54(2), 54-77.

Pappas, C. (2014, October 3). 11 tips to engage and inspire adult learners. eLearning Industry. https://elearningindustry.com/11-tips-engage-inspire-adult-learners

Regional Educational Laboratory Midwest. (n.d.). Profiles of select clinically oriented teacher preparation programs. Institute of Education Sciences.

The Sustainable Funding Project. (2016). For the Public Good: Quality Preparation for Every Teacher. Bank Street College of Education.

Tinto, V. (1994). Leaving college: Rethinking the causes and cures of student attrition (2nd ed.) The University of Chicago Press.

U.S. Department of Education. (2021, March). Teacher Shortage Areas. U.S. Department of Education: Teacher Shortage Areas Reports. https://tsa.ed.gov/\#/reports

Walker, T. (2019, April 3). Teacher shortage is "real and growing, and worse than we thought." National Education Association. https://www.nea.org/advocating-for-change/new-from-nea/teachershortage-real-and-growing-and-worse-we-thought

Walsh, F., Abi-Nader, J., \& Poutiatine, M. I. (2005, Spring). What do adult learners experience in a teacher certification program? Journal of Adult Education. 34(1), 6-21. 


\section{Appendix A}

\section{Accelerated Master of Education Program Overview: Sample Course Plan}

\begin{tabular}{|c|c|c|c|c|c|c|}
\hline \multicolumn{2}{|c|}{ SEMESTER } & \multicolumn{2}{|r|}{ ELEMENTARY COURSES } & \multicolumn{2}{|r|}{ SECONDARY COURSES } & \multirow{2}{*}{$\frac{\text { CREDITS }}{3}$} \\
\hline Sat & Fall & 501 & Intro to Education & 501 & Intro to Education & \\
\hline online & Fall & 202 & Lesson/Unit Planning & 202 & Lesson/Unit Planning & 1 \\
\hline Monday & Fall-Q1 & 566 & Classroom Management & 566 & Classroom Management & 3 \\
\hline Monday & Fall-Q2 & 520 & Literacy I/II & 508 & Secondary Curriculum & 3 \\
\hline Sat & Spring & 579 & Inclusion & 579 & Inclusion & 3 \\
\hline Monday & Spring - Z & 541 & Literacy II/III & 553 & Secondary Educ Practicum & 3 \\
\hline Monday & Spring - Z & MS-271 & Math for Elementary & 554 & Content Area Literacy & 3 \\
\hline Sat & Summer & 543 & Literacy for Diverse Learners & 543 & Literacy for Diverse Learners & 3 \\
\hline Monday & Summer & 596 & School \& Society & 596 & School \& Society & 3 \\
\hline \multirow[t]{2}{*}{ Monday } & Summer & 561 & Assessing Student Learning & 561 & Assessing Student Learning & 3 \\
\hline & & & & & & 28 \\
\hline
\end{tabular}

Note. Monday classes are offered as evening courses to support working/teaching adult students

\section{Master of Education Graduate Degree Requirements}

Candidates wishing to complete the additional coursework needed for a Master of Education graduate degree must do so within 5 years from the date their cohort program begins and after initial certification (offered consistently on Monday evenings):

- $\quad$ EN-510 Research Methods, Design \& Analysis (3 credits)

- EN-511 Thesis: Data Collection (2 credits)

- EN-512 Thesis: Data Analysis (2 credits)

- EN-513 Thesis: Research Presentation (1 credit) 


\section{Appendix B}

\section{Professional Disposition Expectations \\ Danielson Domain 4 (Danielson Group, 2019)}

4a. Engages in meaningful self-evaluation and reflection; Receptive to feedback-You are a reflective practitioner. You don't shy away from constructive criticism, but instead seek out others' suggestions for professional growth and conduct regular self-assessments. You accept criticism calmly and integrate feedback. You accept responsibility for your successes and your mistakes.

4b. Maintains accurate and organized records/work-As a professional educator, you generate various data, are privy to a vast amount of cumulative, confidential and common information, and regularly receive requests for input and completion of forms, duties, and other tasks. You keep information accurate, organized, and secure so that it is ever safe and easily located and interpreted.

4c. Uses mature and sensitive communication with all stakeholders (peers, supervisors, support professionals, students, and parents)-You use various methods of communication as a tool to seek out opportunities to build positive relationships with others. You listen to others with empathy and work to understand diverse perspectives. Your respect for others is reflected in the way you talk, write, and listen. You are able to communicate clearly and effectively in a variety of formats and demonstrate appropriate interpersonal, listening, and communication skills.

4d. Maintains positive relationships, building community and collaborating effectively with stakeholders (peers, supervisors, support professionals, students, and parents) consistently demonstrating sensitivity to diversity and displaying respect for others-You seek out opportunities to build positive relationships with others. You treat everyone with respect. You seek creative solutions through consensus. Your actions and attitude make it clear to others that you respect and value every student, every person. You create an educational environment that values diversity and which addresses the unique needs of each individual.

4e. Grows and develops professionally-As an educator you recognize the importance of being a lifelong learner and practice this belief by developing, at a minimum, an annual personal professional development plan, seeking out and participating in professional development, as well as supporting and participating in the professional community of your own school, that of the district, and the wider state and national educational arenas.

\section{4f. Shows Professionalism}

4f1. Maintains confidentiality and adheres to professional ethics-You are informed of and follow the Department of Education professional Code of Ethics for teachers. You do not talk about students or colleagues inappropriately. You maintain student confidentiality.

4f2. Arrives on time and is well prepared; manages time well-You are prompt and well-prepared for class/meetings. Assignments and project work is on time and complete. You contact faculty, supervising and cooperating teachers, etc. if you will be late or absent.

4f3. Maintains a professional appearance-You come to your education courses and field placements appropriately dressed. Jeans and casual clothes are acceptable, but they should not be dirty, sloppy, or physically revealing. You maintain good grooming and hygiene at all times.

4f4. Exhibits a positive and professional attitude; maintains poise, especially in emotional and stressful settings-Your behavior, attitude, and comments should reflect a positive, constructive approach. 
You participate fully in discussions and class activities. You demonstrate resourcefulness, initiative, and independence. When faced with difficult situations, you maintain your professional poise. Your reactions are thoughtful and cautious, not impulsive. You seek positive, appropriate outlets for your emotions.

4f5. Displays confidence and enthusiasm-Even if you are nervous, your language-spoken or unspoken-conveys an attitude of enthusiasm and eagerness to learn. You come to class or your field placement eager to engage and contribute. about developments and change in the field of education and learning. The journal includes research and related content that examine current relevant educational issues and processes. The aim is to provide readers with knowledge and with strategies to use that knowledge in educational or learning environments. JERAP focuses on education at all levels and in any setting, and includes peer-reviewed research reports, commentaries, book reviews, interviews of prominent individuals, and reports about educational practice. The journal is sponsored by The Richard W. Riley College of Education and Leadership at Walden University, and publication in JERAP is always free to authors and readers. 